\title{
Screening and optimization of culture conditions of Nannochloropsis gaditana for omega 3 fatty acid production
}

\author{
S. Abirami ${ }^{1}$, S. Murugesan ${ }^{1 *}$, V. Sivamurugan ${ }^{2}$, S. Narender Sivaswamy ${ }^{3}$ \\ ${ }^{1} \mathrm{PG}$ and Research Department of Botany, Division of Algal Biotechnology and Bionano Technology, Pachaiyappa's College, Chennai, Tamil Nadu, India. \\ ${ }^{2} \mathrm{PG}$ and Research Department of Chemistry, Pachaiyappa's College, Chennai, India. \\ ${ }^{3}$ SynkroMax Biotech Pvt Ltd, Chennai. Tamil Nadu, India.
}

\section{ARTICLE INFO}

Article history:

Received on: 23/03/2017

Accepted on: 08/05/2017

Available online: 19/06/2017

Key words:

Nannochloropsis gaditana, optimization, omega 3 fatty acids, EPA.

\begin{abstract}
Omega-3 fatty acids are essential fatty acids which are necessary for human health obtained only through diet. The three types of omega-3 fatty acids are involved in human physiology are alpha linolenic acid found in plant oils (ALA), eicosapentaenoic acid, and docosahexaenoic acid (EPA; DHA) both are commonly found in biological sources of marine origin. Marine algae and phytoplankton are primary sources of omega-3 fatty acids. Among the microalgae, Nannochloropsis have been identified for the high EPA content. It is very important to reduce the economic value of the range of products, fuel to pharma from the high lipid productivity strains. In the present study, we have explored a simple preliminary screening method by enrichment technique for selecting oleaginous microbes and optimized several culture parameters with maximum algal growth observed when cultured in $\mathrm{f} / 2$ media and at optimal temperature $25^{\circ} \mathrm{C}$. Further high yield of biomass and lipid content with $8.6 \mathrm{~g} / \mathrm{L}$ and $0.17 \mathrm{~g} / \mathrm{dry}$ wt (17\%) respectively were achieved when using urea as an economical nitrogen source. 0.9\% EPA was achieved from N.gaditana cultivated in laboratory conditions. This study paved for future opportunities of large scale production of omega 3 fatty acids from Nannochloropsis gaditana and suggested further optimization of culture conditions in photobioreactor systems would yield maximum omega 3 fatty acids in commercialization aspects.
\end{abstract}

\section{INTRODUCTION}

Nannochloropsis is an excellent and highly respected microalgae because of its nutritional value and the ability to produce valuable secondary metabolites such as pigments such as zeaxanthin, astaxanthin and polyunsaturated fatty acids (PUFA). PUFAs are essential fats required to the body and acquired indirectly from the PUFAs rich foods. For instance, the foods containing high PUFAs such as omega-3 include fishes, vegetable oils, nuts (especially walnuts), flax seeds, flaxseed oil, and leafy vegetables. Efficient medium composition for microalgae growth needs to be developed, to enhance the biomass and lipid productivity. After preliminary screening and optimization of culture parameters, statistical optimization was applied to the optimization of multiple variables in the fermentation processes with acceptable results [1].
Microalgae have an excellent composition of carbohydrate, protein, and fats that are widely used to meet food needs and the public's health. They can be cultured either photoautotrophically or heterotrophically [2, 3]. Nannochloropsis is one of the most promising microalgae for accumulating maximum lipids. Intensive cultivation for the production of large quantities of microalgae biomass requires a proper harvesting technique. One of the major problems in large scale production of microalgae is the development of efficient separation of cells from culture broth and also to maintain their viability and bioactivity prior to use in the field [4]. Fatty acid profile of N. gaditana was found to be naturally high in EPA and devoid of docosahexaenoic acid (DHA), thereby providing an opportunity to maximize the efficacy of EPA production [5]. Asfouri Nadia Yasmine et al suggested that tradeoffs between growth, pigments and lipid yields as well as culture success can ultimately decide what nitrogen sources and temperature to use [6].

* Corresponding Author

Email:smurugesan5@gmail.com 
With this background, in the present study we focused on importance of $N$. gaditana for its high PUFA content, thriving a simple screening protocol for selection of oleaginous microbes, optimizing of various culture conditions to enhance biomass and omega 3 fatty acid production of $N$. gaditana, under laboratory cultivation.

\section{MATERIALS AND METHODS}

\subsection{Sample collection}

Nannochloropsis gaditana was isolated from the offshore water of the Pondicherry Coast of Southeast India using $25 \mu \mathrm{m}$ plankton net. The samples were brought to the laboratory and inoculated in the $\mathrm{f} / 2$ medium (Table 1) and kept at $24 \pm 1^{\circ} \mathrm{C}$ under $30 \mathrm{Em}^{-2} \mathrm{~s}^{-1}$ light intensity using fluorescent bulbs where light intensity was detected by lux meter in 12/12 light and dark cycle. The isolation and purification were done using algal culturing techniques [7]. The isolated N.gaditana was also cultured and maintained in the conway medium under the laboratory conditions for optimization studies (Table 2).

Table 1: Composition of $\mathrm{f} / 2$ media.

\begin{tabular}{|c|c|}
\hline Composition of $\mathrm{f} / 2$ media & \\
\hline Chemical composition & $\mathrm{mg} / \mathrm{L}$ \\
\hline \multicolumn{2}{|l|}{ Macronutrients } \\
\hline $\mathrm{NaNO}_{3}$ & 75 \\
\hline $\mathrm{NaH}_{2} \mathrm{PO}_{4} \cdot 4 \mathrm{H}_{2} \mathrm{O}$ & 5 \\
\hline Fe-EDTA & 5 \\
\hline $\mathrm{Na}_{2} \mathrm{SiO}_{3} .9 \mathrm{H}_{2} \mathrm{O}$ & 30 \\
\hline \multicolumn{2}{|l|}{ Micro trace elements } \\
\hline $\mathrm{CuSO}_{4} .5 \mathrm{H}_{2} \mathrm{O}$ & 0.0098 \\
\hline $\mathrm{ZnSO}_{4} .7 \mathrm{H}_{2} \mathrm{O}$ & 0.022 \\
\hline $\mathrm{COCl}_{2} \cdot 6 \mathrm{H}_{2} \mathrm{O}$ & 0.010 \\
\hline $\mathrm{MnCl}_{2} \cdot 4 \mathrm{H}_{2} \mathrm{O}$ & 0.180 \\
\hline $\mathrm{Na}_{2} \mathrm{MoO}_{4} 2 \mathrm{HO}$ & 0.006 \\
\hline \multicolumn{2}{|l|}{ Vitamins } \\
\hline Thiamine & 0.1 \\
\hline Biotin & 0.5 \\
\hline B12 & 0.5 \\
\hline
\end{tabular}

Table 2: Composition of Conway media.

\begin{tabular}{|c|c|}
\hline \multicolumn{2}{|c|}{ Composition of Conway media } \\
\hline Chemical composition & $\mathrm{mg} / \mathrm{L}$ \\
\hline \multicolumn{2}{|l|}{ Macronutrients } \\
\hline $\mathrm{Na}_{2}$ EDTA & 45.0 \\
\hline $\mathrm{NaNO}_{3}$ & 100.0 \\
\hline $\mathrm{H}_{3} \mathrm{BO}_{3}$ & 33.6 \\
\hline $\mathrm{Na}_{2} \mathrm{HPO}_{4}$ & 20.0 \\
\hline $\mathrm{MnCl}_{2} \cdot 4 \mathrm{H}_{2} \mathrm{O}$ & 0.36 \\
\hline $\mathrm{FeCl}_{3} \cdot 6 \mathrm{H}_{2} \mathrm{O}$ & 1.3 \\
\hline \multicolumn{2}{|l|}{ Micro trace elements } \\
\hline $\mathrm{ZnCl}_{2}$ & 2.1 \\
\hline $\mathrm{CaCl}_{2}$ & 2.0 \\
\hline$(\mathrm{NH} 4) 6 \mathrm{Mo} 7 \mathrm{O}_{24} \cdot 4 \mathrm{H}_{2} \mathrm{O}$ & 0.9 \\
\hline $\mathrm{CuSO}_{4} .5 \mathrm{H}_{2} \mathrm{O}$ & 2.0 \\
\hline \multicolumn{2}{|l|}{ Vitamins } \\
\hline Vitamin B12 & 10 \\
\hline Vitamin B1 & 200 \\
\hline
\end{tabular}

\subsection{Identification of Nannochloropsis gaditana}

The Nannochloropsis gaditana was identified based on their morphological features as observed under a compound microscope [8]. Semipermanent slides of the samples were prepared with DPX (mixture of distyrene (a polystyrene), a plasticiser (tricresyl phosphate), and xylene) mountant and used for identification.

\subsection{Screening and isolation of oleaginous cultures}

Log phase culture was grown in $f / 2$ medium in natural seawater under continuous illumination and nitrogen deprived condition at $28^{\circ} \mathrm{C}$ for 5 days. This mixture allows the amount of oleaginous microbes and content of lipids to reach a certain level. Enriched culture was then transferred to usual medium and grown without illumination for three to five days. Cells were then enumerated by colony count, turbidimetric method and biomass determination. The strains which have shown stable cell counts and biomass as same as before the screening step, those strains were carried to further optimization [9]

\subsection{Growth study and media optimization}

Nannochloropsis gaditana was grown in two sterile $\mathrm{f} / 2$ medium [10] and Conway [11], in 50\% artificial sea water, $40 \mathrm{mM}$ Tris $\mathrm{HCl}, \mathrm{pH}$ 8. Maintenance and growth of cultures were performed using the same medium supplemented with $10 \mathrm{~g} /$ liter of plant agar purchased from Himedia. Growth experiments were performed in erlenmeyer flasks using orbital shaking; starting from a $50 \mathrm{~mL}$ optimally grown culture transferred to $450 \mathrm{~mL}$ of $\mathrm{f} / 2$ medium in $1000 \mathrm{~mL}$ flasks and kept for 25 days at 2000 lux and $25{ }^{\circ} \mathrm{C}$ for incubation. Cell count, biomass and lipid content were recorded at every 4 days interval.

\subsection{Preparation of microalgae inoculums and mass cultures}

A stock culture of $N$. gaditana (approximately $1 \times 10^{5}$ cells $\mathrm{mL}^{1}$ ) was cultured in an Elenmeyer flask with $800 \mathrm{~mL}$ working volume of $\mathrm{f} / 2$ medium under 2000 lux at $25^{\circ} \mathrm{C}$. Exponential phase culture was inoculated into $3 \mathrm{~L}$ pumpkin flask containing $2000 \mathrm{~mL}$ enriched sea water. After the $4^{\text {th }}$ day, 2500 $\mathrm{mL}$ was used as a seed culture and inoculated into $17.5 \mathrm{~L}$ media with bubbling for air supply. Indoor mass culture was carried out with 20 L carbouys.

\subsection{Cell count and biomass determination}

The algal cell density was measured everyday by counting by a haemocytometer and a light microscope. Growth curves were plotted against days and 106 cells $/ \mathrm{ml}$ of cell number. $25 \mathrm{ml}$ of algal culture were filtered through a membrane filtration apparatus; pre-weighed cellulose acetate filters $(0.2 \mu \mathrm{m})$ and Whatmann GF/C glass microfiber filters $(91.2 \mu \mathrm{m})$. The filter containing algal biomass was washed thrice with $25 \mathrm{~mL}$ of isotonic solution of $0.65 \mathrm{M}$ ammonium formate [12] to remove excess salt. Then the filter was placed in the moisture analyzer and its dry weight was recorded after drying at $100^{\circ} \mathrm{C}$ for $\sim 8 \mathrm{~min}$. The dry weight of the sample was calculated after subtracting the initial filter paper weight from the total weight.

\subsection{Harvesting of algal cells}

Nannochloropsis culture media were taken in a large beaker of $10 \mathrm{~L}$ and the $\mathrm{pH}$ was adjusted using $2 \mathrm{M} \mathrm{NaOH}$ solution 
and the $\mathrm{pH}$ was measured with a bench top $\mathrm{pH}$ meter. In this study the culture media, $\mathrm{pH}$ was adjusted to $10 \pm 0.5$ [13]. The $\mathrm{pH}$ adjusted culture was then transferred immediately into a separate flask or narrow mouth containers for dewatering. The collected cell suspension was slightly acidified with diluted hydrochloric acid to remove sodium salts and was further dewatered such that to separate maximum water from the algal mass. The final algal concentrate were spread on plates for air drying.

\subsection{Determination of biomass and lipid content}

Major pigments were extracted using acetone solvent mixture in combination with the ultrasonic method [14]. Algal lipids were extracted by the procedures similar to the Folch method chloroform/methanol $(2: 1, \mathrm{v} / \mathrm{v})$ containing $0.1 \%$ BHT (butylated hydroxyl toluene) as an antioxidant was added and mixed vigorously for $1 \mathrm{~min}$ then left at $4{ }^{\circ} \mathrm{C}$ overnight. One $\mathrm{mL}$ of $0.9 \%$ sodium chloride was added and mixed again. The organic phase containing lipids was collected. The residual extract was extracted with $2 \mathrm{~mL}$ dichloromethane. Organic phase extracts were pooled and dried under nitrogen and subjected to saponification by mixing with $50 \%$ sodium hydroxide in methanol at $100^{\circ} \mathrm{C}$ for 30 min. The mixture was cooled and poured into crushed ice and 40 $\mathrm{mL}$ of water added. The mixture was shaken with $4 \mathrm{~mL}$ ethyl ether to wash of the unsaponified materials. Further, the suspension was subjected to methylation by adding methanolic hydrochloride solution. Fatty acid methyl esters were then collected by mixing with the extraction solvent containing hexane and tert-butyl methyl ether [15]. Finally the solvent phase was evaporated and stored for estimation of fatty acids by chromatopgraphy.

\section{RESULTS AND DISCUSSION}

Currently, optimizing the culture parameters of microalgae for improving biomass and lipid content has been considered as the major factor for the sustainable product development. The algal lipids were widely used in several industrial applications and enhancing the biomass is also to be considered as the major bottleneck in economic concern. In the present study, optimal temperature, nitrogen source yielded the maximum biomass and lipid content. The main objective of the present study was to optimize the culture conditions and identify the microalgae for the production of omega 3 fatty acids. In agreement with the present study [16] have reported that $C$. protothecoides has significantly enhanced the final cell concentration from 4.9 to $31.2 \mathrm{~g} / \mathrm{L}$, while increasing the glucose concentrations in the culture medium with only a slight reduction in the cell yield $(0.49-0.39 \mathrm{~g} / \mathrm{g})$. In addition, [17] have reported that Nannochloropsis sp., could utilize the carbon sources for their mixotrophic and heterotrophic growth. Moreover, the glucose is the most commonly used carbon sources in microalgae cultivation as it has enhanced the lipid production [18]. It is proved that the microalgae species $C$. protothecoides [19], Crypthecodium cohnii [20] are having the capacity to uptake carbohydrates directly and transforming them into lipids under nitrogen starvation. Nannochloropsis recognized as a good potential source of EPA (20:5), an important polyunsaturated fatty acid for the prevention of several diseases. In the current study, oleaginous algae were screened by an enrichment technique where the cultures were exposed to nitrogen starvation stress condition with abundant carbon source.

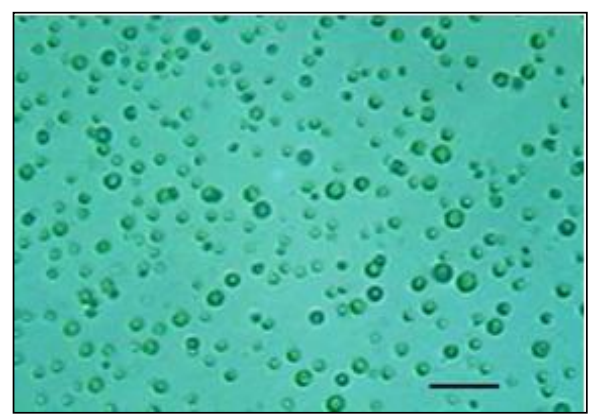

Fig. 1: Nannochloropsis gaditana under light microscope.

As nutrients and environmental factors are crucial components in algal production, they have to be optimized efficiently for higher lipid productivity. An optimal nutrient condition is attributed to the combined effect of both concentration and source of nutrient [21]. Preliminary investigations on various parameters were employed to cultivate $N$. gaditana under different medium (Fig. $2 \& 3$ ). The maximum biomass was observed in $f / 2$ culture medium using artificial seawater $(0.22 \mathrm{~g} / \mathrm{L})$ compared to Conway medium. Further, the optimization studies were also carried out for optimal temperature, nitrogen source with respect to biomass and lipid production. A highest lipid yield of $69 \mathrm{mg} / \mathrm{L}$ was achieved when grown at $25^{\circ} \mathrm{C}$ whereas, $2.3 \mathrm{mg} / \mathrm{L}$ at $37^{\circ} \mathrm{C}$ (Fig.4) .

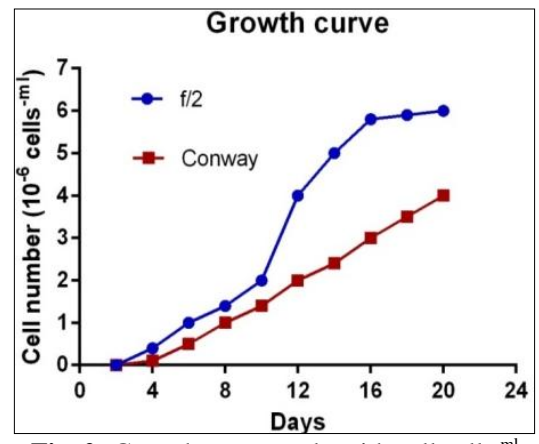

Fig. 2: Growth curve study with cell cells ${ }^{-m l}$

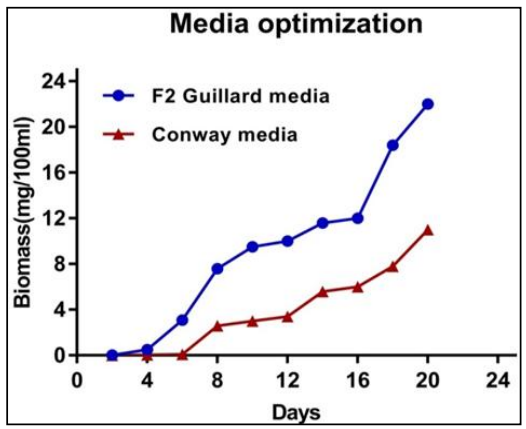

Fig. 3: Media optimization with biomass count $10^{-6}$ content. 


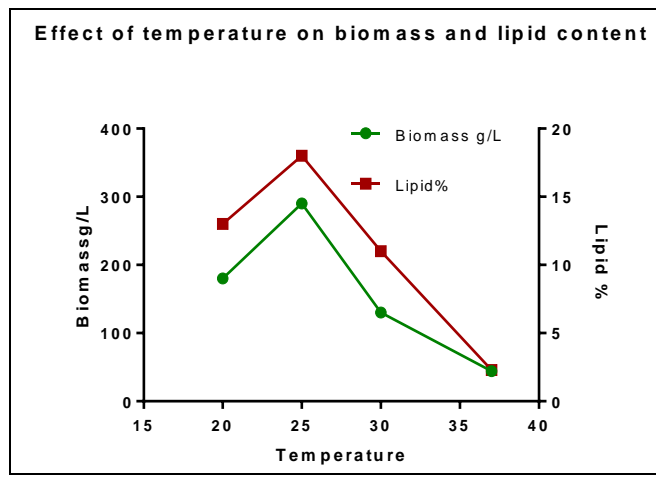

Fig. 4: Effect of temperature on biomass and lipid content.

Influence of nitrogen sources on biomass and lipid content by cultivation under various concentrations of sodium nitrate and urea (Figs. 5 \& 6). As stated by Danesi and Soletto urea is used as a economical nitrogen source than nitrate and had no effect on the final chlorophyll content of the cultures [22]. Nitrate effect was studied by supplementing sodium nitrate at different concentrations and found nitrate concentration about $0.6 \mathrm{~g} / \mathrm{L}$ shown high biomass and lipid yield.

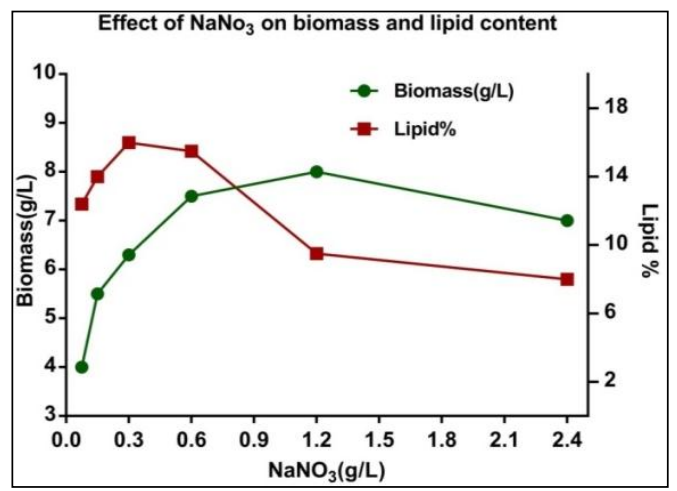

Fig. 5: Effect of $\mathrm{NaNO}_{3}$ on biomass and lipid content.

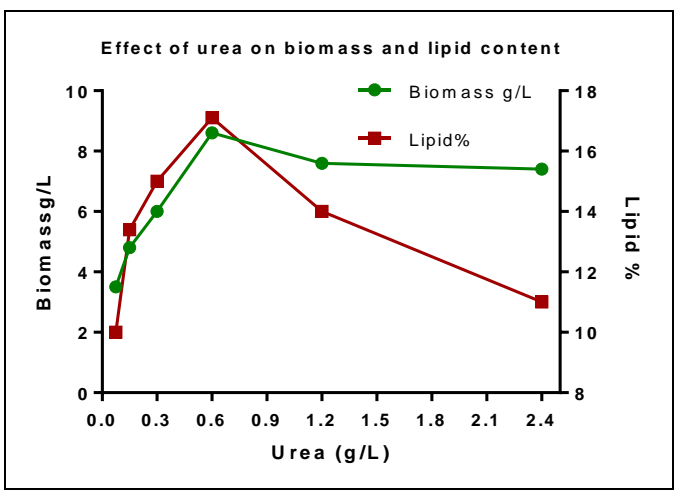

Fig. 6: Effect of urea on biomass and lipid content.

Torre et al., (2003), has demonstrated that Spirulina platensis could utilize urea in fed-batch and batch culture [23]. Fidalgo et al., (1998) also recommended the use of urea for marine microalga Isochrysis galbana resulted in higher fatty acid contents than the use of nitrate and nitrite[24]. Similarly, the growth rate and total lipid content of $N$. gaditana also varied with the level of urea concentration in during the cultivation compared with sodium nitrate. The highest biomass and lipid yield have shown $8.6 \mathrm{~g} / \mathrm{L}$ and $0.17 \mathrm{~g} / \mathrm{dry}$ weight, respectively, when using urea in mass cultivation with optimized culture conditions.

Cells were harvested by the flocculation method by altering the $\mathrm{pH}$. Algal mass obtained were shade dried and powdered after vacuum drying. Algal biomass obtained was used for solvent lipid extraction and the final extract was stored at $-20^{\circ} \mathrm{C}$ with addition to $0.1 \%$ BHT (Butylated hydroxy toluene) as antioxidants.

The crude lipid extract was then subjected for fatty acid extraction method followed by methylation for the production of fatty acid methyl esters which were suitable for gas chromatography. Fatty acid profile of N.gaditana cultivated under culture conditions is given in Table 3. Nannochloropsis is a potential source of EPA and several attempts have been made to improve the algal EPA production by optimizing the medium composition[25,26]. Interestingly, in this study a notable increase in EPA content was recorded in heterotrophic culture condition and our study adds strength. In addition, improving fatty acid synthesis is a promising strategy for lipid accumulation in algal cells. Prominently, some acyl-CoA synthase, diacylglycerol kinase, and glyceraldehyde-3-phosphate dehydrogenase, which were played a major role in glycolysis, acetyl CoA synthesis, and TAG accumulation, respectively, were considered as key sites for controlling of lipid synthesis [27]. The results showed that the fatty acid profile of N.gaditana was altered under these culture conditions. According to Selvakumar (2014), eicosapentaenoic acid (n-3, C20:5) 5\% was achieved by outdoor cultivation for biodiesel production but no EPA production under the indoor cultivation [28]. But, in the present study, we have achieved about $0.9 \%$ of EPA in indoor cultivation using carbouys (Table 3). However, in the present study, the optimized medium for cultivation of $N$. gaditana showed a considerable increase in eicosapentaenoic acid (EPA) content $(0.9 \mathrm{~g})$. Further, enhancement in yield would be possible with the proper culture medium in a temperature controlled system in large scale. Additionally stearic acid content was found to be high (2\%) followed by alpha linolenic acid (1.8\%) plant source of omega 3 fatty acids were obtained.

Table 3: Fatty acid composition of N.gaditana lipid extract.

\begin{tabular}{|c|c|c|}
\hline \multicolumn{3}{|c|}{ Fatty acid composition in N.gaditana extract } \\
\hline Fatty acid & Lipid No & $\mathrm{g} / 100 \mathrm{~g}$ \\
\hline Palmitic acid & C16:0 & 1.335 \\
\hline Margaric acid & $\mathrm{C} 17: 0$ & 0.845 \\
\hline Stearic acid & $\mathrm{C} 18: 0$ & 2.224 \\
\hline Oleic acid & $\mathrm{C} 18: 1$ & 1.456 \\
\hline Linoleic acid & $\mathrm{C} 18: 2$ & 1.835 \\
\hline Alpha linolenic acid & $\mathrm{C} 18: 3$ & 0.939 \\
\hline Moroctic acid & $\mathrm{C} 18: 4$ & 0.1145 \\
\hline Eicosapentaenoic acid & $\mathrm{C} 20: 5$ & 0.9 \\
\hline
\end{tabular}

\section{CONCLUSION}

In conclusion, the results of this study have demonstrated the growth performance of N.gaditana in different growth parameters like media contents, temperature, and nitrate 
concentrations. The conditions were optimized to improve the biomass and lipid production. The expected results were achieved when cultivated in $\mathrm{f} / 2$ media at $25^{\circ} \mathrm{C}$. It was found that urea an economical and effective agricultural byproduct which could be readily replace the nitrate source by achieving high lipid content than the sodium nitrate. This study defended that algae-based processes seem to be reliable and economically attractive source of omega-3 fatty acid, especially EPA,DHA and can provide an efficient way for the large scale production.

\section{Financial support and sponsorship: Nil.}

Conflict of Interests: There are no conflicts of interest.

\section{REFERENCES}

1. Tran, H.L. Kwon, J.S. Kim, Z.H. Oh, Y. Lee, C.G. Statistical optimization of culture media for growth and lipid production of Botryococcus braunii LB572 Biotechnol. Bioprocess Eng. 2010; 15: 277-284.

2. Ryckebosch, E., Bruneel, C., Muylaert, K., \& Foubert, I. Microalgae as an alternative source of omega-3 long chain polyunsaturated fatty acids. Lipid Technology. 2012; 24(6): 128-130.

3. Thangapandi Marudhupandi, Ramamoorthy Sathishkumara, Thipramalai Thankappan Ajith Kumara. Heterotrophic cultivation of Nannochloropsis salina for enhancing biomass and lipid production. Biotechnology Reports. 2016; 10: 8-16.

4. Harith, Z.T., Yusoff, F. M., Mohamed, M. S., Mohamed Din, M. S. and Ariff, A. B., Effect of different flocculants on the flocculation performance of microalgae, Chaetoceros calcitrans, cells, African Journal of Biotechnology. 2009, 8 (21): 5971-5978

5. Tang Y, Zhang Y, Rosenberg JN, Betenbaugh MJ, Wang F. Optimization of One-Step In Situ Transesterification Method for Accurate Quantification of EPA in Nannochloropsis gaditana. Appl. Sci. 2016, 6, 343.

6. Asfouri Nadia Yasmine, Djalt Houari Sarra, Maroc Fatma, Lamara Sid-Ahmed Chawki, Baba Hamed Mohammed Bey, Abi-AyadSidiMohammed El-Amine. Cultivation of marine microalga Nannochloropsis gaditana under various temperatures and nitrogen treatments: effect on growth, lipid and pigment content. Int. J. Biosci. 2017; 10(3): 209-216.

7. Andersen R.A. Algal culturing techniques. Elsevier Academic Press, London. 2005, p. 578.

8. Iyengar M., Desikachary OP, Volvocales TV. I.C.A.R. Monograph. New Delhi. 1981; pp. 525

9. Li SL, Lin Q, Li XR, Xu H, Yang YX, Qiao DR, Cao Y. Biodiversity of the oleaginous microorganisms in Tibetan plateau, Braz $\mathrm{J}$ Microbiol. 2012 Apr; 43(2):627-34. doi: 10.1590/S151783822012000200026

10. Guillard, R.R.L. Culture of phytoplankton for feeding marine invertebrates. pp 26-60. In Smith W.L. and Chanley M.H (Eds.) Culture of Marine Invertebrate Animals. Plenum Press, New York, USA . 1975.

11. Lananan F, Jusoh A, Ali N, Lam SS, Endut A. Effect of Conway Medium and $\mathrm{f} / 2$ Medium on the growth of six genera of South China Sea marine microalgae. Bioresour Technol. 2013 Aug;141:75-82. doi: 10.1016/j.biortech.2013.03.006.

12. Navid R. Moheimani, Mark P. McHenry, Karne de Boer, Parisa A. Bahri. Biomass and Biofuels from Microalgae, Advances in Engineering and Biology. 2015.

13. Ferriols VMEN, Aguilar RO. Efficiency of various flocculants in harvesting the green microalgae Tetraselmis tetrahele (Chlorodendrophyceae: Chlorodendraceae). AACL Bioflux. 2012, 5 (4).
14. Wiltshire, K.H., Boersma, M., Möller, A. et al. Extraction of pigments and fatty acids from the green alga Scenedesmus obliquus (Chlorophyceae). Aquatic Ecology. 2000 34: 119. doi:10.1023/A:1009911418606

15. Ranjith Kumar R., Hanumantha Rao P., and Arumugam M. Lipid extraction methods from microalgae: a comprehensive review. Front Energy Res, 2015; 2: 61.

16. XM Shi, HJ Liu, XW Zhang, F Chen. Production of biomass and lutein by Chlorella protothecoides at various glucose concentrations in heterotrophic cultures. Proc. Biochem. 1999; 34: 341-347.

17. Fang X., Wei C., Zhao-Ling C., Fan O. Effects of organic carbon sources on cell growth and eicosapentaenoic acid content of Nannochloropsis sp. J. Appl. Phycol., 2004; 16: 499-503.

18. A. Singh, Ward OP. Production of high yields of docosahexaenoic acid by Thraustochytrium roseum ATCC 28210. J. Ind. Microbiol. Biotechnol., 1996; 16(6): 370-373.

19. Wu QY, Yin S, Sheng GY, Fu JM. A comparative study of gases generated from stimulant thermal degradation of autotrophic and heterotrophic Chlorella Prog. Nat. Sci. 1992; 3: 435-440.

20. Arumugam M, Agarwal A, Arya MC, Ahmed Z. Influence of nitrogen sources on biomass productivity of microalgae Scenedesmus sp. Bioresour Technol. 2013; 131: 246-9. doi 10.1016/j.biortech.2012.12.159.

21. Binaghi, L., Lodi, A., Carvalho, J. C. M. and Converti, A. 2005. Batch and fed-batch cultivations of Spirulina platensis using ammonium sulphate and urea as nitrogen sources. Aquaculture 243: $217-224$

22. Torre P, Sassano CEN, Sato S, Converti A., Gioielli LA and Carvalho JCM. Fed-batch addition of urea for Spirulina platensis cultivation thermodynamics and material and energy balances. Enzyme Microl and Technol. 2003; 33: 698 - 707.

23. Fidalgo, J.P., Cid, A., Torres, E., Suken, A. and Herrero, C. Effect of nitrogen source and growth on proximate biochemical composition, lipid classes and fatty acid profile of marine microalga Isochrysis galbana. Aquaculture. 1998; 166(1-2): $105-116$

24. $\mathrm{Hu} \mathrm{HH}, \mathrm{Gao}$ KS. Optimization of growth and fatty acid composition of a unicellular marine picoplankton, Nannochloropsis sp., with enriched carbon sources Biotechnol. Lett., 2003; 25 :421-425.

25. Hoshida, H., Ohira, T., Minematsu, A. et al. Accumulation of eicosapentaenoic acid in Nannochloropsis sp. in response to elevated $\mathrm{CO}_{2}$ concentrations. J Appl Phycol. 2005; 17: 29. doi:10.1007/s10811-005-5512-9

26. Li YJ, Fei XW, Deng XD. Novel molecular insights into nitrogen starvation-induced triacylglycerols accumulation revealed by differential gene expression analysis in green algae Micractinium pusillum Biomass Bioenergy. 2012; 42: 199-211.

27. Selvakumar P, Umadevi K. Mass Cultivation of Marine Micro alga Nannochloropsis gaditana KF410818 Isolated from Visakhapatnam offshore and Fatty Acid Profile Analysis for Biodiesel Production, J. Algal Biomass Utln. 2014; 5 (1): 28-37.

\section{How to cite this article:}

Abirami S, Murugesan S, Sivamurugan V and Narender Sivaswamy S. Screening and optimization of culture conditions of Nannochloropsis gaditana for omega 3 fatty acid production. J App Biol Biotech. 2017; 5 (03): 013-017. 